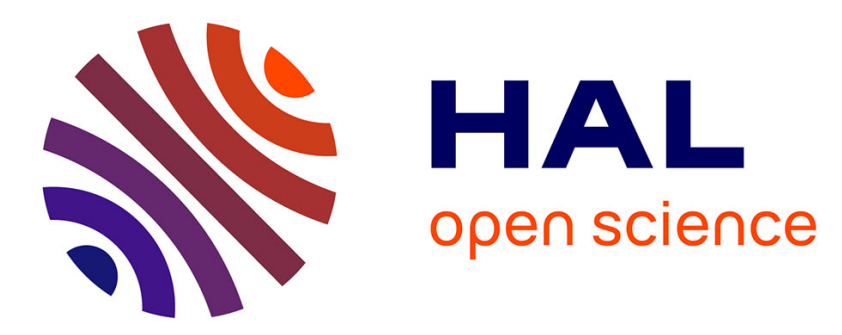

\title{
Determination of the characteristic parameters of tension-compression asymmetry of Shape Memory Alloys using full-field measurements
}

Yves Chemisky, Rachid Echchorfi, Fodil Meraghni, Nadine Bourgeois, Boris Piotrowski

\section{To cite this version:}

Yves Chemisky, Rachid Echchorfi, Fodil Meraghni, Nadine Bourgeois, Boris Piotrowski. Determination of the characteristic parameters of tension-compression asymmetry of Shape Memory Alloys using fullfield measurements. European Symposium on Martensitic Transformations (ESOMAT), Sep 2012, Saint-Pétersbourg, Russia. 10.4028/www.scientific.net/MSF.738-739.281 . hal-01366683

\section{HAL Id: hal-01366683 https://hal.science/hal-01366683}

Submitted on 15 Sep 2016

HAL is a multi-disciplinary open access archive for the deposit and dissemination of scientific research documents, whether they are published or not. The documents may come from teaching and research institutions in France or abroad, or from public or private research centers.
L'archive ouverte pluridisciplinaire $\mathbf{H A L}$, est destinée au dépôt et à la diffusion de documents scientifiques de niveau recherche, publiés ou non, émanant des établissements d'enseignement et de recherche français ou étrangers, des laboratoires publics ou privés. 


\title{
Determination of the characteristic parameters of tension-compression asymmetry of Shape Memory Alloys using full-field measurements
}

\author{
Yves Chemisky ${ }^{1, \mathrm{a}}$, Rachid Echchorfi ${ }^{1, \mathrm{~b}}$, Fodil Meraghni ${ }^{1, \mathrm{c}}$, \\ Nadine Bourgeois ${ }^{2, \mathrm{~d}}$, Boris Piotrowski ${ }^{1, \mathrm{e}}$ \\ ${ }^{1}$ Arts et Metiers ParisTech, LEM3 laboratory - CNRS, 4, rue Augustin Fresnel 57078 Metz, FRANCE \\ 2Universite de Lorraine, LEM3 laboratory - CNRS, Ile du Saulcy, 57000 Metz, FRANCE \\ ayves.chemisky@ensam.eu, brachid.echchorfi@ensam.eu, cfodil.meraghni@ensam.eu, \\ dnadine.bourgeois@univ-lorraine.fr, ${ }^{\mathrm{d}}$ boris.piotrowski@ensam.eu
}

Keywords: Identification, Shape Memory Alloys, transformation surface, tension-compression asymmetry.

\begin{abstract}
In this work, a method for the identification of the transformation surface of Shape Memory Alloys based on full field measurements is presented. An inverse method coupled with a gradientbased algorithm has been developed to determine the characteristic parameters of the transformation surface. The constitutive equations of the chosen model that capture the macroscopic behavior of Shape Memory Alloys are first presented. The material parameters, to be identified, that are characteristic of the tension-compression asymmetry of the alloy are detailed. The identification algorithm, based on full field measurements obtained by Digital Image Correlation (DIC) and numerical simulation by Finite Element Analysis are introduced. The identification algorithm is validated using a numerically generated strain field on a Meuwissen-type specimen.
\end{abstract}

\section{Introduction}

With the design of new complex devices that utilizes Shape Memory Alloys (SMAs) and to take advantage of their large recoverable strains, SMA components are more and more subjected to multiaxial loadings [1]. It has been shown that the transformation characteristics of SMAs are loadingpath dependent. In particular, both the critical stress for the onset of transformation and the maximal transformation strain exhibit a tension-compression asymmetry. This phenomena has been observed experimentally [2, 3] on NiTi and copper-based alloys, and using a micromechanical model [4]. To design advanced devices in SMAs that are subjected to multiaxial loadings, the chosen constitutive model should include such effects. Several authors have proposed a formulation that accounts for the tension-compression asymmetry $[4,3,5,6]$. All of these models are based on the $J_{2}-J_{3}$ invariants of the stress or the transformation strain tensor. In a recent work, Chemisky et al. [7] have shown that such a formulation can be explicitely defined by the two maximum transformation strain in tension and compression, respectively. The identification of such parameters usually requires one tensile and one compression test on a SMA that is initially in the austenitic state. However, these tests are difficult to perform with a good accuracy on similar specimens. It is therefore difficult to determine the maximum strain in tension and compression on samples with the same thermomechanical history (processing, heat treatments). In the present work, a procedure is established to identify the parameters that are characteristic of the tension-compression asymmetry based on full-field measurements. It is shown that heterogeneous strain fields obtained with DIC (Digital Image Correlation), where each material point has a different loading path is sufficient to identify the asymmetric parameters using inverse methods. Utilizing the constitutive model proposed by Chemisky et al. [7], finite element simulations are carried out to predict the strain fields on the area of interest of the specimen. An optimization algorithm is further required to minimize the error between the experimental and numerically-computed strain fields. 


\section{Constitutive model and description of tension-compression asymmetry}

The formulation of the phenomenological constitutive model of Chemisky et al. [7] is based on the description of a thermodynamic free energy potential employing a chosen set of complementary independent state variables (external and internal). Thermodynamic transformation forces are derivated from this free energy potential.

One of the characteristic parameters is the saturated transformation strain that depends on lattice shear, incompatibilities between variants, texture of the polycrystal and formed martensite microstructure. Moreover, experimental data have shown different critical stress for the onset of stress-induced transformation between tension and compression. To represent this phenomenon in the case of superelasticity, a phenomenological transformation surface was derived from Prager equation. Several authors have also proposed similar yield surface definitions $[8,9,2,5]$. In the constitutive model of Chemisky et al., it is assumed that amplitude of the average transformation strain tensor $\bar{\varepsilon}^{T}$ reaches a maximum:

$$
\left|\bar{\varepsilon}^{T}\right| \leqslant \varepsilon_{S A T}^{T}
$$

To capture the tension-compression asymmetry, the physical limitation (eq. 1) is expressed using a modified formulation of Prager equation written in terms of the average transformation strain tensor invariants:

$$
\varepsilon_{\text {sat }}^{T}=K\left(1+\beta \frac{J_{3}}{J_{2} \frac{3}{2}}\right)^{\frac{1}{n}} \quad \text { with } \quad J_{2}=\frac{1}{2} \bar{\varepsilon}_{i j}^{T} \bar{\varepsilon}_{i j}^{T}, \quad J_{3}=\frac{1}{3} \bar{\varepsilon}_{i j}^{T} \bar{\varepsilon}_{j k}^{T} \bar{\varepsilon}_{k i}^{T}
$$

$K$ and $\beta$ parameters are related to the tension and compression maximum tranformation strain, considering the components of the average transformation strain tensor in tension and compression $\varepsilon_{\text {trac }}^{T}$ and $\varepsilon_{\text {comp }}^{T}$ :

$$
\varepsilon_{i j}^{T}=\varepsilon_{\text {trac }}^{T}\left(\begin{array}{ccc}
1 & 0 & 0 \\
0 & -\frac{1}{2} & 0 \\
0 & 0 & -\frac{1}{2}
\end{array}\right), \quad \varepsilon_{i j}^{T}=\varepsilon_{c o m p}^{T}\left(\begin{array}{ccc}
-1 & 0 & 0 \\
0 & \frac{1}{2} & 0 \\
0 & 0 & \frac{1}{2}
\end{array}\right) .
$$

Parameters $K$ and $\beta$ are thus written:

$$
K=\varepsilon_{\text {trac }}^{T}\left(1+\frac{\beta}{\alpha}\right)^{-\frac{1}{n}}, \quad \beta=\left(\frac{1-\gamma}{\gamma+1}\right) \alpha, \quad \gamma=\left(\frac{\varepsilon_{\text {comp }}^{T}}{\varepsilon_{\text {trac }}^{T}}\right)^{n} .
$$

$\alpha$ is a constant value coming from $J_{2}$ and $J_{3}$ invariants definition $(\alpha \simeq 2.6)$ and $\gamma$ is the ratio between the maximum transformation strain in tension and compression, at the $n$-rank.

Note that the shape of the transformation surface in the principal stress space depends on the values of the two maximum transformation strains, $\varepsilon_{\text {trac }}^{T}$ and $\varepsilon_{\text {comp }}^{T}$ and the exponent $n$. While this last parameters is characteristic of the shape of the transformation surface, it does not modify the tension-compression assymetry. Therefore this parameter is set to a constant value (5) in this study.

\section{Identification procedure}

It has been shown that the identification of parameters that are characteristic of the tension - compression asymmetry can be reduced to the determination of the maximum transformation strain in tension and in compression, respectively. The next step is to develop an identification procedure to extract them simultaneously from experimental data. The Finite Element Model Updating method (FEMU) is applied and consists in solving a nonlinear optimization problem, where a cost function is defined from the square difference between experimental data and numerical simulation results. The optimisation problem considered here consists in minimizing a cost function utilized by [10], 
which is constructed from the sum of the square difference between the measured and the numerically computed components of the strain tensor and the difference between the measured and numerically simulated reaction force. The components of the strain tensors (two longitudinal strains and one shear strain) are evaluated utilizing the DIC technique. The addition of the difference in the reaction force to the cost function brings additional information to determine the sensitivity of each parameter and allows the regularization of ill-posed problem if a displacement boundary condition is applied.

The inverse identification algorithm utilizes the Levenberg-Marquardt algorithm to compute the update of the set of parameters [11, 12]. This algorithm, as all the gradient-based algorithms, requires the sensitivity matrix that represents the sensitivity of each strain component regarding to a fluctuation of each parameter. Since the reaction force enters in the formulation of the cost function, the senstivity matrix includes also the partial derivatives of the components of the reaction force with respect to each parameter. Finite element analysis is utlized to determine numerically all the components of this matrix, by means of finite difference technique [13].

\section{Validation of the identification procedure}

The validation of the identification procedure consists in the determination of the maximum transformation strain in tension and compression based on numerically generated strain fields to represent the experimental data. Since the parameters utilized to generate the numerical strain fields are know, it is possible to check if the identification algorithm retrieve the values utilized for the generation of such strain fields. The numerical simulation is performed on a Meuwissen-type specimen subjected to pure tension [14]. A similar identification procedure on Meuwissen-type specimens has been utilized to successfully identify the parameters characteristic of the evolution of damage in composite materials [10]. The specific shape of this specimen induces an heterogeneous strain field, with a number of different local loading paths. The heterogeneous nature of the strain field is indeed necessary to identify parameters that are characteristic of the asymmetry. The reference strain field has been generated numerically at a temperature of $323 \mathrm{~K}$ with the reference parameters detailed in Table 1 . These parameters are described in [7]:

Table 1: Reference material parameters for the selected NiTi alloy

\begin{tabular}{cccccc}
\hline$E(\mathrm{MPa})$ & $\nu$ & $\varepsilon_{\text {trac }}^{T}$ & $\varepsilon_{\text {comp }}^{T}$ & $\left.B_{f}\left(\mathrm{MPa} . K^{-1}\right)\right)$ & $b_{r}\left(\mathrm{MPa} . K^{-1}\right)$ \\
67926 & 0.34 & 0.05 & 0.04 & 9.42 & 9.42 \\
\hline$M_{S}(\mathrm{~K})$ & $A_{f}(\mathrm{~K})$ & $H_{f}(\mathrm{MPa})$ & $n$ & & \\
265 & 295 & 8.2 & 5 & & \\
\hline
\end{tabular}

An uniaxial displacement of $1 \mathrm{~mm}$ has been imposed on one side of the specimen, while the other side is clamped. The identification procedure utilizes strain fields periodically recorded (10 records). The initial guessed parameters are set up to be $\varepsilon_{\text {trac }}^{T}=0.03$ and $\varepsilon_{c o m p}^{T}=0.03$. These values have been selected since they are common average values for the transformation strain in shape memory alloys. Figure 1 shows the transformation surface for plane stress conditions in the two principal stress plane and the uniaxial behavior at $323 \mathrm{~K}$. Note that the change in the maximum strain in tension and compression induces a change in the critical stress for the onset and for the end of transformation, in the maximum transformation strain, in the transformation hardening and also the hysteresis width. Therefore, the material response is strongly different between with the initial set of parameters or the reference parameters. A second set of values $\left(\varepsilon_{\text {trac }}^{T}=0.1\right.$ and $\left.\varepsilon_{\text {comp }}^{T}=0.1\right)$ have been selected to ensure that the identification procedure is able to retrieve the reference parameters even if the initial guessed values are perceptibly different. 

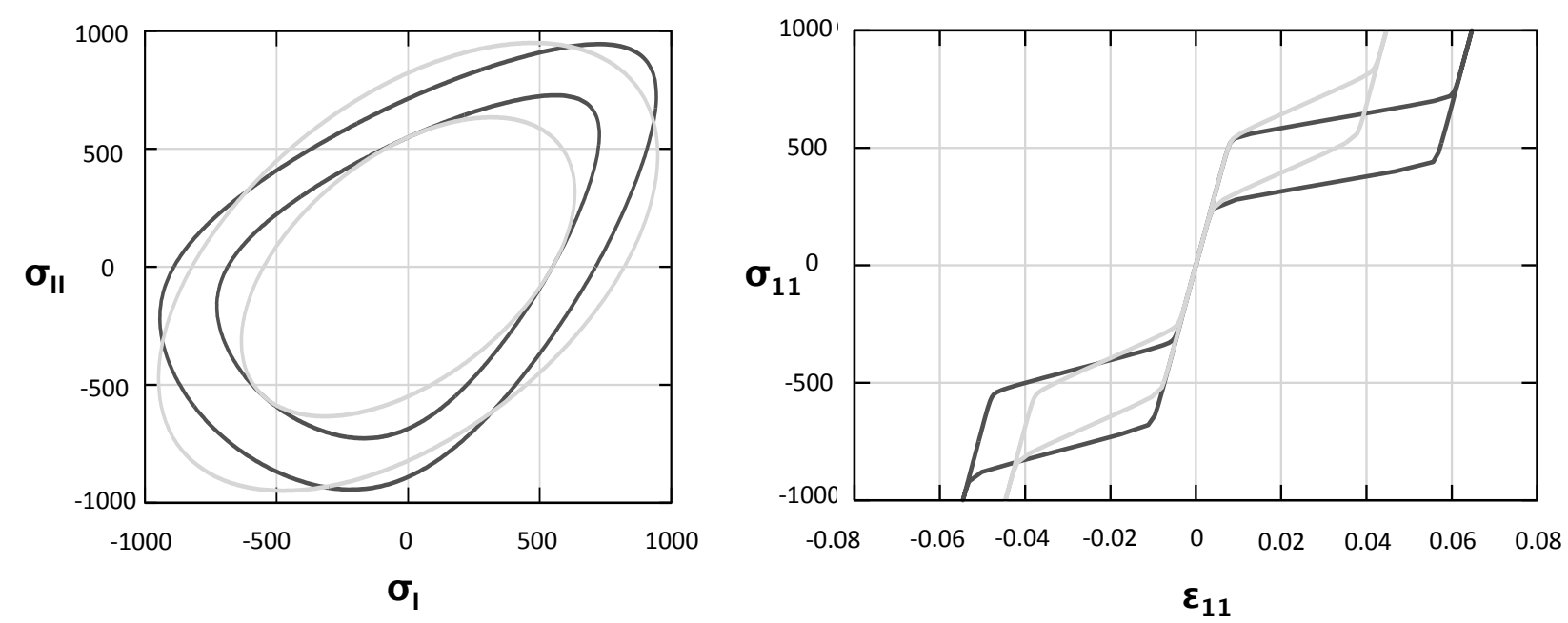

Fig. 1: (Left) Transformation surfaces for the onset and the completion of the forward transformation and (Right) uniaxial stress-strain response with the set of initial parameters $\left(\varepsilon_{\text {trac }}^{T}=0.03\right.$ and $\varepsilon_{\text {comp }}^{T}=$ 0.03 , in grey $)$ and the reference parameters $\left(\varepsilon_{\text {trac }}^{T}=0.05\right.$ and $\varepsilon_{\text {comp }}^{T}=0.04$, in black $)$

The strain fields $\left(\varepsilon_{11}, \varepsilon_{22}\right.$ and $\left.\gamma_{12}=2 \varepsilon_{12}\right)$ numerically computed for a displacement of $2 / 3 \mathrm{~mm}$ are presented in figure 2 , for the case of the initial guessed parameters and the reference parameters. A significant difference is observed, especially for the component $\varepsilon_{11}$ of the strain tensor. The inverse identification procedure is able to retrieve the reference parameters after 7 iterations with a relative error on each parameter that is less than $1 \%$, and retrieve them exactly after 9 iterations. For the second set, the reference parameters are retrieved after 9 iterations with a relative error on each parameter that is less than $1 \%$, and retrieve them exactly after 11 iterations.

\section{Conclusion}

In this work, an inverse identification procedure has been developed to determine the material parameters of SMAs that are characteristic of the tension-compression asymmetry. The maximum transformation strain in tension and compression have been related to the transformation surface of Shape Memory Alloys. An identification procedure has been developped to obtain, from full field measurements, the characteristic parameters of the tension-compression asymmetry observed in SMAs. A validation test has been performed on numerically generated strain fields using a set of reference material parameters. It has been shown that the identification procedure is able to retrieve exactly the reference parameters, even if the values of initial guessed parameters are quite different from the reference ones. Further work will focus on the validation of the identification procedure varying all the parameters the experimental determination of strain fields on different alloys to accurately predict their tension-compression asymmetry characteristic parameters. 

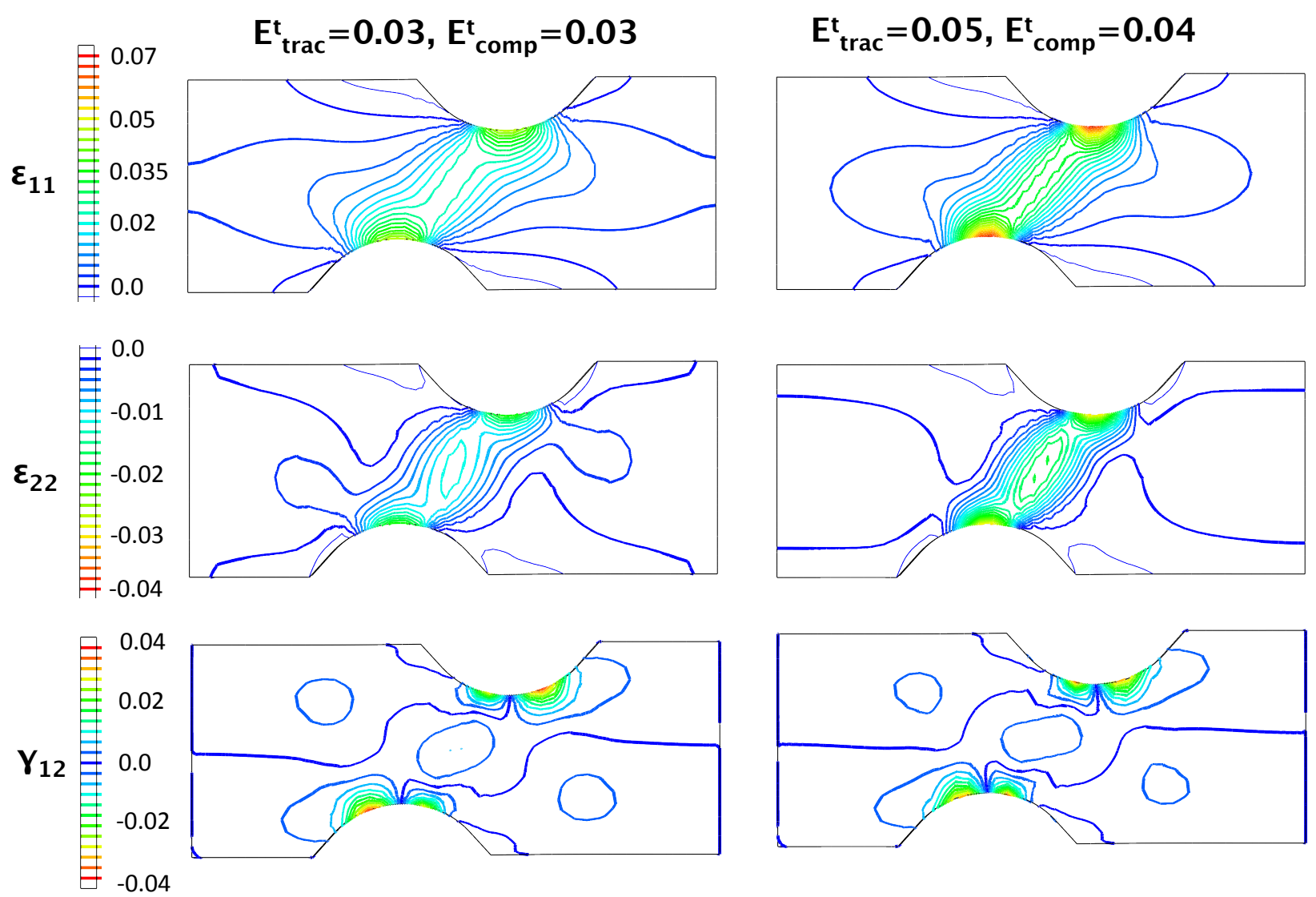

Fig. 2: Strain fields on the surface of the Meuwissen sample computed numerically with the set of initial parameters $\left(\varepsilon_{\text {trac }}^{T}=0.03\right.$ and $\left.\varepsilon_{c o m p}^{T}=0.03\right)$ and the reference parameters $\left(\varepsilon_{\text {trac }}^{T}=0.05\right.$ and $\left.\varepsilon_{\text {comp }}^{T}=0.04\right)$

\section{References}

[1] D.C. Lagoudas: Shape Memory Alloys - Modeling and Engineering Applications(Springer US, 2008).

[2] F.L. Orgéas and D. Favier: Acta Materialia Vol. 46 (1998), p. 5579

[3] C. Lexcellent, A. Vivet, C. Bouvet, S. Calloch and P. Blanc: J. Mech. and Phys. of Solids Vol. 50 (2002), p. 2717

[4] E. Patoor, M. El Amrani, A. Eberhardt and M. Berveiller: J. Phys. IV Vol. 5 (1995), p. 495

[5] M.A. Qidwai and D.C. Lagoudas: Int. J. of Plasticity Vol. 16 (2000), p. 1309

[6] B. Peultier, T. Ben Zineb and E. Patoor: Materials Science and Engineering: A Vol. 481-482 (2008), p. 384

[7] Y. Chemisky, A. Duval, E. Patoor and T. Ben Zineb: Mechanics of Materials Vol. 43 (2011), p. 361

[8] C. Lexcellent, M.L. Boubakar, C. Bouvet, S. Calloch: Int. J. of Solids and Structures Vol. 43 (2006), p. 613

[9] S. Calloch, K. Taillard, S. Arbab Chirani, C. Lexcellent and E. Patoor: Mat. Science \& Eng. A Vol. 438-440 (2006), p. 441 
[10] F. Meraghni, H. Nouri, N. Bourgeois, C. Czarnota and P. Lory: Procedia Engineering Vol. 10 (2011), p. 2110

[11] K. Levenberg: The Quarterly of Applied Mathematics Vol. 2 (1944), p. 164

[12] D.W. Marquardt: Journal of the Society for Industrial and Applied Mathematics Vol. 11 (1963), p. 431

[13] O. Ghouati and J.C. Gelin: Computational Materials Science Vol. 21 (2001), p. 57

[14] M.H.H Meuwissen, C.W.J. Oomens, F.P.T. Baaijens, R. Petterson and J.D. Janssen: Journal of Materials Processing Technology Vol. 7 (1998), p. 204 